\title{
Práticas pedagógicas com a web 2.0 no ensino fundamental
}

\author{
Patrícia Brandalise Scherer Bassani* \\ Débora Nice Ferrari Barbosa** \\ Patrícia Thoma Eltz
}

\section{Resumo}

\begin{abstract}
A presente pesquisa ${ }^{1}$, de abordagem qualitativa, busca apresentar um panorama das práticas pedagógicas com o uso da web 2.0, desenvolvidas nos anos finais do ensino fundamental. A abordagem privilegiada neste artigo é exploratória. A coleta de dados envolveu uma pesquisa bibliográfica com base nos trabalhos publicados nos anais do Simpósio Brasileiro de Informática na Educação (SBIE, 2012) e do Workshop em Informática na Educação (WIE, 2012), bem como nos artigos publicados na Revista Novas Tecnologias na Educação (Renote, 2012 - números 1, 2 e 3 do volume 10). Foram analisados, ao todo, 256 artigos. Os resultados apontam que o número de pesquisas compartilhadas na área acadêmica, envolvendo o uso de ferramentas web 2.0 na educação, em especial nos anos finais do ensino fundamental, ainda é bastante reduzido.
\end{abstract}

Palavras-chave: Web 2.0. Artefato tecnológico digital. Ensino fundamental. Ambientes pessoais de aprendizagem.

\section{Introdução}

O ciberespaço é o novo meio de comunicação que surge da interconexão mundial dos computadores. Lemos afirma que o "ciberespaço é um ambiente mediático, como uma incubadora de ferramentas de comunicação" (2007, p. 136) e, portanto, "mais que um fenômeno técnico, o ciberespaço é um fenômeno social" (2007, p. 138).

Estudos apontam que o ciberespaço suporta tecnologias intelectuais que amplificam, exteriorizam e modificam numerosas funções cognitivas, como a memó-

\author{
Recebido: 05/04/2013 - Aprovado: 12/07/2013 \\ http://dx.doi.org/10.5335/rep.2013.3556
}

\footnotetext{
Doutora em Informática na Educação (UFRGS). Professora titular do Programa de Pós-Graduação em Diversidade Cultural e Inclusão Social da Universidade Feevale. E-mail: patriciab@feevale.br

* Doutora em Ciência da Computação (UFRGS). Professora adjunta do Programa de Pós-Graduação em Diversidade Cultural e Inclusão Social da Universidade Feevale. Bolsista de Produtividade do CNPq. E-mail: deboranice@feevale.br.

*** Mestra em Educação (UFRGS). Doutoranda do Programa de Pós-Graduação em Diversidade Cultural e Inclusão Social da Universidade Feevale. E-mail: patricia_eltz@yahoo.com.br.
} 
ria, a imaginação, a percepção e o raciocínio (LEVY, 2001; ALAVA, 2002). Essas tecnologias intelectuais favorecem novas formas de acesso à informação, além de novos estilos de raciocínio e conhecimento. Além disso, por meio desse ambiente, essas tecnologias podem ser compartilhadas. Portanto, o ciberespaço é, hoje, um espaço que possibilita o compartilhamento de ideias e sentimentos (LEMOS, 2007).

Lemos destaca, ainda, que o ciberespaço pode ser entendido à luz de duas perspectivas, cada vez mais integradas: como um ambiente simulado, onde os sujeitos entram e se encontram, e como o conjunto de redes de computadores interligadas, a internet. Logo, o ciberespaço é "uma interface entre a estrutura de máquinas de comunicação e a massa de informações" (LEMOS, 2007, p. 132) produzida pelo conjunto dos sujeitos que por ali circulam. Ele se constrói "pela disseminação da informação, pelo fluxo de dados e pelas relações sociais aí criadas” (LEMOS, 2007, p. 137).

Pode-se analisar, portanto, o ciberespaço a partir de uma perspectiva cultural, uma vez que se constrói pela interconexão entre os sujeitos, as tecnologias e a informação, tornando-se um elemento da cultura, da sociedade. Assim, tendo em vista que permeiam a sociedade atual, as tecnologias estão transformando a relação entre as pessoas e seu meio social, criando uma cultura cibernética inerente ao nosso dia a dia, onde o real e o virtual coexistem e completam-se, reforçando o que Lemos chama de um fenômeno social ou cibercultura.

Assim, as ações de produzir, distribuir e compartilhar caracterizam-se como os princípios fundamentais do ciberespaço (LEMOS, LEVY, 2010). Essas ações são mediadas/possibilitadas, nesse espaço cibernético, por diferentes ferramentas tecnológicas, que podem ser entendidas como artefatos culturais, sendo, também, parte da cultura. Um artefato cultural pode ser qualquer objeto produzido que possui um significado e transmite informações sobre o sujeito e sua cultura; consequentemente, representa modos de ser e de estar para os sujeitos e seu meio social. Ao olhar-se para o ciberespaço a partir de uma perspectiva cultural, pode-se entender os diferentes recursos tecnológicos que fazem parte do meio como artefatos culturais, só que agora tecnológicos e digitais. Assim, neste estudo, denominam-se as diferentes ferramentas tecnológicas, os sistemas e os recursos do ciberespaço como artefatos tecnológicos digitais. Entende-se, portanto, que estes possibilitam a produção de conteúdos, o compartilhamento de informações, além da comunicação e das relações sociais no ciberespaço.

Sistemas compartilhados na web, essencialmente caracterizados pela possibilidade de participação e intervenção dos sujeitos, possibilitando a interação de muitos-para-muitos, constituem a base do conceito de web 2.0. Conforme O'Reilly (2007), a web 2.0 é a rede como plataforma, abarcando todos os dispositivos a ela 
conectados. As aplicações web 2.0 são aquelas que utilizam as possibilidades dessa plataforma, criando efeitos na rede através de uma arquitetura de participação. Chama-se esse tipo de aplicação de software social. Conforme Spyer, "o termo social software é usado para se referir ao tipo de programa que produz ambientes de socialização pela internet, ele é que está por trás da colaboração online" (2007, p. 21), como redes de relacionamento (Orkut, Facebook), blogs, microblogs (Twitter), wikis, compartilhamento de arquivos e outros.

Do ponto de vista da educação, o ciberespaço não pode ser reduzido a um espaço tecnológico que permite assegurar melhor a transmissão passiva do saber, mas deve ser entendido como um espaço social de comunicação e de trabalho em grupo (ALAVA, 2002). Pisani e Piotet apontam que os atuais usuários da web não são mais navegadores passivos, que apenas consomem o conteúdo disponibilizado por especialistas. Para eles, os usuários atuais "propõem serviços, trocam informações, comentam, envolvem-se, participam” (2010, p. 16). Esses novos usuários, que não se contentam em navegar, mas também produzem conteúdo na web, são chamados de web atores. Assim, pensar a educação no ciberespaço tende a (re) colocar em pauta as ideias de aprendizagem colaborativa (ALAVA, 2002).

Portanto, as diferentes aplicações da web 2.0, como blogs, wikis, sites de redes sociais ou de compartilhamento de arquivos, podem ser utilizadas no contexto educativo, uma vez que apresentam diversas possibilidades de interação, de comunicação e de descoberta/troca de informações (McLOUGHLIN; LEE, 2011).

Entretanto, percebe-se que as escolas brasileiras ainda não exploram o potencial da internet, especialmente em relação à capacidade de interação e comunicação da web 2.0, sobretudo em razão de dificuldades de infraestrutura e de formação de professores. Desde 2008, o Comitê Gestor da Internet (CGI) no Brasil realiza, anualmente, a pesquisa sobre o uso das Tecnologias da Informação e Comunicação na Educação (TIC Educação).

Os resultados dessa pesquisa em 2011 mostram que, apesar de todo o investimento realizado para a introdução das TICs na educação, ${ }^{2}$ o uso efetivo do computador e da internet pelos professores nas atividades com os alunos ainda se caracteriza como um grande desafio, uma vez que as atividades mais frequentes em sala de aula são aquelas em que os docentes menos empregam as tecnologias. A TIC Educação 2011, também, abordou o uso das TICs nas escolas particulares. Os resultados demonstraram que, embora as escolas particulares estejam mais avançadas do que as escolas públicas em relação à disponibilidade da infraestrutura tecnológica, a frequência das atividades realizadas com os alunos é semelhante nos dois casos: "Isso denota que os desafios para aproveitar o potencial das TICs são os mesmos para escolas públicas e particulares, porque poucos professores declararam usá-las nas atividades de ensino" (TIC EDUCAÇÃO, 2012, p. 95). 
Segundo Lemos (2010), as tecnologias móveis e sem fio estão transformando a relação entre as pessoas e os espaços urbanos em que elas vivem, criando novas formas de mobilidade. Com isso, a sociedade vai se tornar cada vez mais ubíqua, pois essas tecnologias estão permitindo que os espaços se tornem ambientes de interconexão, envolvendo o sujeito em plena mobilidade, envolvendo objetos e pessoas. A possibilidade de o sujeito levar consigo o objeto de estudo, ou poder acessá-lo de qualquer lugar, potencializa o uso de dispositivos móveis na educação, também chamado de aprendizagem com mobilidade - mobile learning (ROSCHELLE, PEA, 2002; SACCOL, 2010).

Segundo Silva e Consolo (2008), a disseminação e o uso das tecnologias móveis, ao possibilitarem novas práticas educacionais e sociais, provocam a reflexão sobre os conceitos de proximidade, distância e mobilidade, bem como a sua reformulação. Conforme as autoras, essas possibilidades tecnológicas permitem que 0 processo educacional também se desenvolva a partir de um conceito que pode ser denominado de "educação móvel e conectada".

Pesquisa recente sobre as tecnologias na educação básica, divulgada no relatório Horizon Report $2012^{3}$ (JOHNSON; ADAMS; CUMMINS, 2012), destaca o uso de dispositivos móveis e aplicativos como uma tendência em curto prazo (nos próximos 12 meses). A versão brasileira do Horizon Report 2012, intitulada Projeto Hori$z o n . b r$, teve por objetivo explorar as tecnologias emergentes e prever o seu impacto potencial no contexto do ensino fundamental e médio brasileiro para o período de 2012 a 2017. Os pesquisadores, também, apontaram como perspectivas tecnológicas em curto prazo (um ano ou menos) o uso de dispositivos móveis, como celulares, smartphones e tablets, além do uso de ambientes colaborativos e de aprendizagem baseada em jogos. "Os ambientes colaborativos são espaços online, muitas vezes baseados na nuvem, onde o foco é facilitar a colaboração e o trabalho em grupo, sem importar onde os participantes estejam" (JOHNSON et al., 2012, p. 7).

O Projeto Horizon.br ainda apontou os desafios para o uso efetivo das TICs no contexto educativo. Conforme a pesquisa, utilizar a tecnologia não é suficiente; também é necessário modificar as metodologias de ensino. Além disso, o processo de formação de professores deve ser modificado para se adaptar aos novos estudantes e às novas tecnologias (JOHNSON et al., 2012).

Dessa forma, considerando o contexto apresentado, como a arquitetura de participação da web está sendo explorada no contexto educativo? Este estudo constitui-se de uma primeira parte de uma pesquisa ${ }^{4}$ que busca investigar o potencial da arquitetura da participação da web 2.0 no processo de ensino e aprendizagem presencial dos anos finais do ensino fundamental. Essa etapa da educação básica foi escolhida para a pesquisa em razão de quatro principais aspectos: 
a) entende-se que o sujeito nessa fase do ensino possui uma autonomia maior para o uso dos artefatos tecnológicos digitais e utiliza-os de forma imbricada à sua cultura, e não como um elemento a ser incorporado;

b) considerando as perspectivas tecnológicas em curto prazo apontadas pelo relatório Horizon Report 2012, entende-se que esses sujeitos utilizam, de forma ampla e massiva, a web, os dispositivos móveis (em especial, os smartphones), as redes sociais e os jogos;

c) esse sujeito está apto, do ponto de vista de idade mínima, para o acesso e o uso de um conjunto maior de ferramentas da web 2.0, tanto para fins pessoais como escolares;

d) é um sujeito mais crítico, participativo e aberto a diferentes propostas metodológicas e formas de ensinar e de aprender.

Portanto, o presente estudo busca apresentar um panorama de como as ferramentas web estão sendo, efetivamente, utilizadas nos anos finais do ensino fundamental, sob a perspectiva da pesquisa acadêmica. Para tanto, foi realizada uma análise dos trabalhos publicados nos anais do Simpósio Brasileiro de Informática na Educação (Sbie, 2012) e do Workshop em Informática na Educação (WIE, 2012), bem como dos artigos publicados na Revista Novas Tecnologias na Educação (Renote, 2012).

O presente artigo parte de uma reflexão sobre a arquitetura de participação da web 2.0 na educação, para, a seguir, apresentar o percurso metodológico da pesquisa.

\section{A arquitetura de participação da web 2.0 na educação}

Conforme O'Reilly (2007), a web 2.0 caracteriza-se como um conjunto de princípios e práticas, sob a perspectiva da arquitetura de participação. Esta se baseia no princípio de que as novas tecnologias potencializam as trocas e a colaboração entre os sujeitos e, nessa perspectiva, a estrutura tecnológica expande-se de maneira conjunta com as interações sociais dos sujeitos que utilizam a internet (COBO-ROMANÍ, 2007). Assim sendo, assume-se, como Pisani e Piotet, que "a web é, ao mesmo tempo, a ferramenta social e o espaço em que as relações ocorrem" (2010, p. 34).

Cobo-Romaní (2007) apresenta uma reflexão sobre o desenvolvimento de aplicações web 2.0 e suas apropriações sociais. A taxonomia proposta pelo pesquisador organiza-se a partir de quatro perspectivas:

a) redes sociais: descreve todas as ferramentas desenvolvidas para trocas sociais, facilitando a formação de comunidades virtuais, como o Facebook; 
b) conteúdos: envolve as ferramentas que favorecem a leitura e a escrita online, assim como a distribuição e o compartilhamento, como blogs e wikis;

c) organização social e inteligente da informação: ferramentas e recursos para localizar, indexar e armazenar as informações e outros recursos da web, como os serviços de busca (por exemplo, o Google), ou marcadores sociais (como o Delicious);

d) aplicações e serviços: diferentes ferramentas para oferecer serviços de valor agregado ao usuário, como e-mail, armazenamento gratuito de dados, entre muitos outros.

Neste estudo, conforme dito anteriormente, as ferramentas da web 2.0 são entendidas como artefatos tecnológicos digitais. Nessa perspectiva, a ferramenta situa-se, para além de um espaço que possibilita a produção e a distribuição de conteúdos educativos, como um espaço relacional de compartilhamento e trocas sociais.

De tal modo, a utilização dessas diferentes ferramentas no contexto educativo pode resultar em inovações pedagógicas, uma vez que oportunizam novas formas de criação coletiva, de compartilhamento de conteúdos de aprendizagem, de comunicação entre alunos e professores, além da criação de ambientes de aprendizagem personalizados e centrados no aluno (CONOLE, 2013). As redes sociais, os blogs e wikis admitem criar e compartilhar conteúdos e interagir com outras pessoas, permitindo a customização, além de uma sensação de pertencimento (SCLATER, 2008).

Entretanto, a utilização dessas diferentes ferramentas de produção, distribuição e compartilhamento é relativamente nova no contexto educativo, e, portanto, os educadores precisam encontrar novas possibilidades de ensinar e aprender, a fim de explorar o seu potencial de fomentar processos de cooperação (BATES, 2011). Além disso, é preciso que esses instrumentos sejam percebidos pelos educadores como um elemento da cultura digital dos educandos. Dessa forma, destaca-se a necessidade e a importância de que os educadores também entendam e vivenciem essa cultura digital, explorando as possibilidades desses artefatos no contexto educativo de maneira natural, significativa e colaborativa.

Neste estudo, adota-se o conceito de cooperação a partir de uma concepção construtivista-interacionista, embasada na perspectiva piagetiana (PIAGET, 1973), na qual a aprendizagem é um processo ao mesmo tempo individual e coletivo, onde o conhecimento não está no sujeito nem no objeto, sendo uma construção individual que emana da interação do sujeito com o seu meio. Piaget (1973) aponta que as trocas interindividuais baseadas em cooperação representam o mais alto nível de socialização, e relações de cooperação envolvem discussão e troca de pontos de vista e implicam igualdade de direito ou autonomia. 
O objetivo do estudo é refletir sobre o uso das ferramentas web 2.0, entendidas como artefatos tecnológicos digitais, nos anos finais do ensino fundamental. Nessa fase escolar os estudantes encontram-se na etapa das operações concretas - entre 7 e 12 anos (PIAGET, 1973). Ao atingir esse nível operacional, a criança torna-se capaz de cooperar, ou seja, não pensa mais somente em função de si, mas da coordenação real ou possível de pontos de vista, tornando-se capaz de discussão, de reflexão e de colaboração.

Tem-se o conhecimento de que o software social possibilita a constituição de redes de cooperação. Estas, na educação, incluem os agrupamentos que emergem a partir das interações produzidas pelos sujeitos em blogs, nas listas de discussão e nas redes sociais que se formam a partir do software social.

O conceito de Personal Learning Environments (PLE ${ }^{5}$ ), ou ambientes pessoais de aprendizagem, vem sendo elaborado a partir de estudos recentes, impulsionados pelo crescimento do software social. Os proponentes de PLE concordam com a necessidade de ampliar o escopo de ferramentas, serviços e conteúdos, de forma que os estudantes possam utilizar todo o potencial da web 2.0, incluindo ferramentas de socialização e compartilhamento de arquivos, blogs, microblogs, wikis e outras, para ampliar o potencial de aprendizagem.

Mota (2009) apresenta um interessante artigo enfocando o surgimento do conceito de PLE. De acordo com o texto, um ambiente virtual de aprendizagem tradicional, que promove uma experiência isolada do mundo, poderia ser substituído por ambientes pessoais de aprendizagem, chamados de PLE, que permitem ao aluno articular experiências em diferentes contextos, a partir das ferramentas da web 2.0.

Castañeda e Adell (2013) apontam que o PLE organiza-se a partir de três partes:

a) ferramentas, mecanismos e atividades para ler: envolvem as fontes de informação em diferentes formatos, como texto, áudio e vídeo; caracterizam-se por sites, blogs, canais de vídeo, newsletters, entre outras;

b) ferramentas, mecanismos e atividades para fazer: são os espaços onde o sujeito pode documentar o processo de reflexão a partir das informações coletadas; são espaços para escrever, refletir e publicar. Como exemplos, os autores citam as ferramentas para escrita, como blogs e wikis, as ferramentas para produção de cartazes, como o Glogster (http://www.glogster.com), e para produção de histórias em quadrinhos, como Pixton (http://www.pixton. com.br);

c) ferramentas, mecanismos e atividades para compartilhar e refletir em comunidades: caracterizam-se como espaços onde é possível conversar e trocar ideias com outros sujeitos, na perspectiva da formação de redes sociais. 
Dessa forma, o PLE caracteriza-se como esse conjunto de ferramentas, fontes de informação, conexões e atividades, que cada sujeito utiliza para aprender (CASTAÑEDA; ADELL, 2013).

De acordo com Downes (2007), a ideia que embasa o conceito de PLE é que o gerenciamento da aprendizagem migra da instituição para o estudante. $\mathrm{O}$ autor sustenta que o PLE e a web 2.0 apoiam-se nos mesmos valores:

a) a emergência das redes sociais e comunidades (aprender em comunidades);

b) a ênfase na criação, e não apenas no consumo;

c) a descentralização do conteúdo e do controle.

Nessa perspectiva, o PLE permite que o aluno não seja apenas um consumidor de recursos/conteúdos, mas também um produtor. Para Downes (2007), o PLE constitui um portal para o mundo, onde os alunos podem explorar e criar, de acordo com seus interesses e direções, interagindo com seus amigos/colegas e em diferentes comunidades. Assim, o PLE pode ser entendido como a manifestação do processo de aprendizagem informal do estudante na web (DOWNES, 2007, COUROS, 2010, MARTINDALE; DOWDY, 2010).

Entretanto, será que esse conceito já está sendo aplicado nas práticas educativas na internet? Este estudo tem por objetivo verificar de que forma as ferramentas web estão sendo utilizadas na educação e refletir de que forma elas podem ser utilizadas na perspectiva do PLE.

\section{0 processo de pesquisa}

A presente pesquisa, de abordagem qualitativa, busca apresentar um panorama das práticas pedagógicas com o uso da web 2.0, desenvolvidas nos anos finais do ensino fundamental.

A abordagem privilegiada neste artigo é a exploratória. A coleta de dados envolveu uma pesquisa bibliográfica com base nos trabalhos publicados nos anais do Simpósio Brasileiro de Informática na Educação (Sbie, 2012) e do Workshop em Informática na Educação (WIE, 2012), bem como nos artigos publicados na Revista Novas Tecnologias na Educação (Renote, 2012 - números 1, 2 e 3 do volume 10). A seleção da amostra levou em conta a relevância dos eventos e da revista no âmbito da Informática na Educação no Brasil. Foram analisados 87 artigos publicados nos anais do Sbie, 48 artigos nos anais do WIE e 121 artigos publicados na Renote. Portanto, foram analisados, ao todo, 256 artigos.

A primeira etapa da coleta de dados consistiu na análise dos títulos e dos resumos dos 256 artigos, buscando-se selecionar apenas os com foco na educação básica. Foram selecionados 40 artigos: 
a) Sbie: oito artigos;

b) WIE: dez artigos;

c) Renote: 22 artigos.

A segunda etapa envolveu a leitura dos 40 artigos na íntegra, a fim de identificar os estudos focados no ensino fundamental, com ou sem o uso da web. Nesse momento, foram encontrados 25 artigos:
a) Sbie: seis artigos;
b) WIE: nove artigos;
c) Renote: dez artigos.

Em um terceiro momento, foram identificados os artigos com foco nos anos finais do ensino fundamental, com ou sem o uso da web, resultando em 12 artigos:

a) Sbie: três artigos;

b) WIE: cinco artigos;

c) Renote: quatro artigos.

Por fim, dentre os 12 artigos acima, apenas cinco abordam o uso da web nos anos finais do ensino fundamental, conforme apresentado:
a) Sbie: nenhum;
b) WIE: três artigos;
c) Renote: dois artigos.

Os dados encontram-se agrupados na Tabela 1.

Tabela 1 - Artigos publicados em 2012

\begin{tabular}{|c|c|c|c|c|c|}
\hline Nível de ensino & Critério & Sbie & WIE & Renote & Total \\
\hline & todos os artigos & 87 & 48 & 121 & 256 \\
\hline educação básica & com/sem web & 8 & 10 & 22 & 40 \\
\hline ensino fundamental & com/sem web & 6 & 9 & 10 & 25 \\
\hline anos finais & com/sem web & 3 & 5 & 4 & 12 \\
\hline $\begin{array}{c}\text { do ensino fundamental } \\
\text { anos finais }\end{array}$ & uso da web & 0 & 3 & 2 & 5 \\
\hline do ensino fundamental & & & & & \\
\hline
\end{tabular}

Assim, dos 87 artigos publicados no Sbie 2012, foram encontrados somente três relacionados com os anos finais do ensino fundamental, mas nenhum deles aborda o uso de ferramentas da web 2.0. No contexto do WIE 2012, dos 48 artigos, somente três estão relacionados com o uso da web 2.0 nos anos finais do ensino fundamental. Por fim, no contexto da Renote 2012, após a análise dos 121 artigos publicados nos números 1, 2 e 3 do volume 10, foram identificados apenas dois que abordam o uso de ferramentas web 2.0 nos anos finais do ensino fundamental. 
O Gráfico 1 mostra o processo decrescente de artigos que abordam o uso da web 2.0 nos anos finais do ensino fundamental, considerando o número total de artigos publicados.

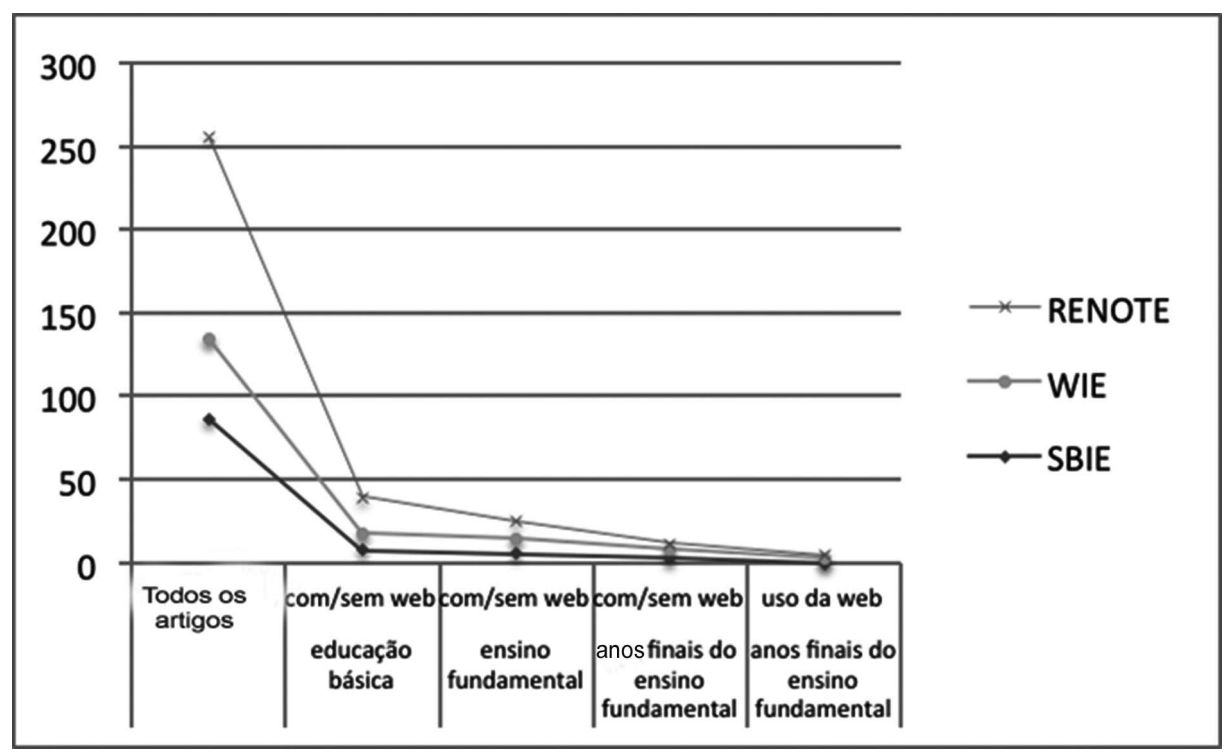

Gráfico 1 - Artigos publicados em 2012

\section{Análise dos resultados}

Além de mapear o número de artigos publicados envolvendo o uso da web 2.0 nos anos finais do ensino fundamental, entende-se que é importante analisar quais ferramentas estão sendo utilizadas e, especialmente, verificar a prática pedagógica proposta.

No contexto do Sbie 2012, não foram encontrados estudos envolvendo o uso da web nos anos finais do ensino fundamental. Os artigos que focam no público-alvo destacado nesta pesquisa envolvem o uso de software educativo.

No âmbito do WIE 2012, foram identificados três artigos que exploram o uso da web 2.0 nos anos finais do ensino fundamental. Dois artigos mostram o uso de blogs e da ferramenta Prezi, e um terceiro descreve a dinâmica de um projeto internacional, envolvendo trocas entre estudantes de diferentes nacionalidades, por meio de um ambiente virtual de aprendizagem.

O blog é um espaço para a criação e para a escrita, onde o participante pode dialogar sobre diferentes assuntos e receber comentários de outros sujeitos que o 
acessarem. Coutinho e Bottentuit Junior (2007) salientam a utilização pedagógica dessa ferramenta como estratégia educativa, proporcionando espaços de intercâmbio, colaboração, debates e integração. Nesse ambiente de troca, de acordo com os autores, há a grande possibilidade de desenvolvimento do pensamento crítico, confronto de ideias, criação de argumentos, entre outros.

O Prezi (www.prezi.com) é um ambiente disponível na modalidade cloud (tecnologia de computação na nuvem) utilizado para a criação de apresentações não lineares e que pode substituir o comumente usado Microsoft Power Point ${ }^{\circledR}$. O Prezi cria apresentações mais dinâmicas, a partir da integração de diferentes mídias, permitindo colaboração online. Também possui suporte para várias tecnologias móveis.

No contexto da Renote 2012, identificou-se apenas dois trabalhos que envolvem o uso de ferramentas web nos anos finais do ensino fundamental. Um deles, desenvolvido com os alunos da $5^{\mathrm{a}}$ série do ensino fundamental (equivale ao $6^{\circ}$ ano), utilizou o ambiente Google Earth para trabalhar os conceitos de geometria plana. O outro, desenvolvido com os alunos de $7^{\underline{a}}$ e $8^{\underline{a}}$ séries, envolve o uso do Pbworks (www.pbworks.com), um ambiente do tipo wiki.

O panorama desvelado neste estudo, por meio da análise dos artigos do Sbie, do WIE e da Renote de 2012, evidencia que o número de pesquisas compartilhadas na área acadêmica, envolvendo o uso de ferramentas web 2.0 na educação, ainda é bastante reduzida. Ao resgatar a pergunta inicial deste estudo - como a arquitetura de participação da web está sendo explorada no contexto educativo? -, percebe-se que as pesquisas documentadas nos anais dos eventos e da revista, aqui analisados, apontam que há um vasto campo de investigação nessa área.

Além disso, é importante destacar que, dos cinco artigos identificados, apenas em um se encontra documentada uma prática pedagógica que explora o potencial de interação e comunicação da web. Assim, os resultados verificados fazem emergir diferentes reflexões e questionamentos sobre o uso das ferramentas web no contexto educativo.

A pesquisa TIC Educação 2011 evidencia que o número de computadores disponíveis nas escolas é pequeno para atender a todos os alunos, que faltam equipamentos conectados à internet e que a velocidade da conexão é baixa. Dessa forma, entende-se que as questões relacionadas à infraestrutura das escolas revelam uma das dificuldades do uso da web nesse contexto.

Em relação ao uso das tecnologias digitais em atividades pedagógicas, os resultados da pesquisa TIC Educação 2011 apontam sua ausência em sala de aula, sendo as atividades mais frequentes aquelas em que os docentes menos usam as tecnologias. Assim, a pesquisa revela que essas técnicas ainda não exercem uma 
presença significativa na aprendizagem, na prática pedagógica e no dia a dia da relação entre professor e aluno. Por outro lado, quanto à formação dos professores para uso das TICs, a pesquisa demonstra que a maioria domina algumas habilidades básicas, encontrando-se no estágio identificado como de "alfabetização digital" (UNESCO, 2009). Acessar e navegar na internet, escrever textos e mover ou copiar arquivos são atividades que a maioria dos professores realiza sem dificuldades. Considerando os dados da pesquisa, é possível inferir que eles atuam mais como espectadores do que como produtores de conteúdo, uma vez que sua principal habilidade é usar um buscador de informações, como o Google, para acesso a conteúdos. Nesse caso, será que o número reduzido de pesquisas documentadas envolvendo atividades com a web 2.0 no ensino fundamental tem relação com a falta de formação específica dos professores para o uso desses recursos?

Compreende-se que a efetiva aplicação das diferentes ferramentas da web 2.0 no contexto educativo perpassa a apropriação tecnológica do professor, no que se refere tanto às habilidades básicas para uso das diferentes tecnologias digitais quanto à vivência na/em rede, de forma a compreender os processos de aprendizagem coletiva. Entretanto, de que forma os professores estão vivenciando esses processos de socialização em rede?

Existem inúmeras ferramentas na web 2.0 que podem ser utilizadas tanto para a criação como para a distribuição e o compartilhamento de conteúdos. Entretanto, destaca-se a importância de compreender essas ferramentas como artefatos tecnológicos digitais. Reconhecê-las como espaços de interação, para além da simples produção de conteúdo educativo, é um importante critério para orientar a proposição de práticas pedagógicas baseadas na cooperação. Nesse sentido, a dificuldade para o uso das ferramentas da web 2.0 pelos docentes, em suas práticas pedagógicas, estaria relacionada a uma questão cultural, em que a cultura digital ainda é um elemento a ser incorporado pelos docentes?

Portanto, considerando-se os resultados levantados na análise dos artigos, conclui-se que o uso de ferramentas web 2.0 no contexto educativo, sob a perspectiva do PLE, ainda se apresenta como uma abordagem inovadora.

\section{Considerações finais}

Neste estudo, parte-se da compreensão de que as ferramentas da web 2.0 caracterizam-se como artefatos tecnológicos digitais carregados de significado e representam modos de ser e estar para os sujeitos e seu meio social. Dessa forma, pensar a educação na cibercultura implica refletir sobre os processos de ensino e de aprendizagem à luz dos princípios do ciberespaço: produzir, distribuir e compartilhar. 
Considerando o relatório da UNESCO (2009), quanto à formação dos professores para uso das TICs, é importante que a educação - e o educador - rompam com o estágio da "alfabetização digital" e vão ao encontro do "aprofundamento" e da "criação" do conhecimento com o uso das TICs. Dessa forma, as tecnologias da web 2.0 passarão a ser, de fato, artefatos tecnológicos digitais. Com isso, caem as fronteiras entre o conhecimento formal e o informal, pois agora o sujeito constrói o conhecimento em interação com a sua cultura e a sociedade digital, a partir de processos de interação potencializados pelos instrumentos tecnológicos. Além disso, o acesso a essas ferramentas por meio de dispositivos móveis amplia os espaços de interação para além do contexto físico da escola e da sala de aula.

Assim, o uso das ferramentas da web 2.0, aliado às tecnologias móveis, torna possível a formação de PLE, de modo que o aluno passa de consumidor a produtor de conhecimento e pode explorar e criar, de acordo com seus interesses e direções, interagindo com seus amigos/colegas em diferentes comunidades (DOWNES, 2007).

Portanto, entendendo a construção do conhecimento a partir de uma perspectiva Piagetiana (1973), na qual a aprendizagem é um processo ao mesmo tempo individual e coletivo, evidencia-se que os diferentes artefatos tecnológicos digitais possibilitam um espaço de produção individual integrado a processos de interação e construção coletiva. Entretanto, em qualquer cenário, é preciso que a educação e os educadores - apropriem-se dessas ferramentas e de suas possibilidades como um elemento natural do processo de ensino e de aprendizagem.

\section{Educational practices using web 2.0 in elementary education}

\section{Abstract}

This study, qualitative approach, aims to present an overview of pedagogical practices developed in the final years of elementary school using web 2.0. The approach privileged in this paper is exploratory. The data were collected from a bibliographical research based on academic papers published in the proceedings of the Brazilian Symposium on Computers in Education (Sbie, 2012), Workshop on Computers in Education (WIE, 2012), and in the journal of New Technologies in Education (Renote, 2012 - numbers 1, 2 and 3, volume 10). Were analyzed, in all, 256 articles. The results show that the amount of academic research involving the use of web 2.0 tools in education, especially in the final years of elementary school, is still very limited.

Keywords: Web 2.0. Digital technological artifact. Elementary education. Personal learning environment. 


\section{Notas}

1 Agradecemos ao Conselho Nacional de Desenvolvimento Científico e Tecnológico (CNPq) pelo apoio financeiro à pesquisa.

2 No âmbito nacional, várias ações governamentais são realizadas pelo Ministério da Educação para impulsionar o uso das TICs no espaço da sala de aula, como o Programa Nacional de Tecnologia Educacional (ProInfo), o Programa Um Computador por Aluno (UCA) e Mídias na Educação.

3 Esse relatório é elaborado, anualmente, a partir de um trabalho colaborativo entre New Media Consortium (NMC), Consortium of School Networking (CoSN) e International Society for Technology in Education (Iste).

$4 \mathrm{O}$ projeto "Ensinar e aprender em/na rede: a arquitetura de participação da web 2.0 no contexto da educação presencial” tem apoio financeiro do CNPq, por meio do edital MCTI/CNPq/MEC/CAPES No 18/2012.

5 PLE encontra tradução em português como "ambientes pessoais de aprendizagem", ou, em espanhol, como "entornos personales de aprendizagem". Entretanto, no meio acadêmico, a sigla PLE ainda se mantém.

\section{Referências}

ALAVA, S. (Org.). Ciberspaço e formações abertas. Porto Alegre: Artes Médicas, 2002.

BATES, T. Understanding web 2.0 and its implications for e-learning. In: LEE, M.; MCLOUGHLIN, C. (Eds.). Web 2.0-based e-learning: applying social informatics for tertiary teaching. Hershey, PA: Information Science Reference, 2011. p. 21-42.

CASTAÑEDA, L.; ADELL, J. La anatomía de los PLEs. In: (Eds.). Entornos personales de aprendizaje: claves para el ecosistema educativo en red. Alcoy: Marfil, 2013. p. 11-27.

COBO-ROMANÍ, C. Mapa de aplicaciones. Una taxonomía comentada. In: COBO-ROMANÍ, C.; PARDO-KUKLINSKI, H. Planeta web 2.0. Inteligencia colectiva o medios fast food. Grup de Recerca d'Interaccions Digitals, Universitat de Vic. México: Flacso, 2007. p. 61-88.

CONOLE, G. Designing for learning in an open world. UK: Springer, 2013.

COUROS, A. Developing personal learning networks for open and social learning. In: VELETSIANOS, G. (Org.). Emerging technologies in distance education. Canada: Athabasca University, 2010. p. 109-128.

COUTINHO, C. P.; BOTTENTUIT JUNIOR, J. B. Blog e wiki: os futuros professores e as ferramentas da web 2.0. In: SIMPÓSIO INTERNACIONAL DE INFORMÁTICA EDUCATIVA (Siie), 9, 2007, Porto, Portugal. Anais... Porto: Siee, 2007. p. 199-204.

DOWNES, S. Learning networks in practice. Inglaterra, 2007. Disponível em: <http://partners. becta.org.uk/upload-dir/downloads/page_documents/research/ emerging_technologies07_chapter2.pdf>. Acesso em: 03 mar. 2010.

JOHNSON, L.; ADAMS, S.; CUMMINS, M. NMC Horizon Report: 2012 K-12 Edition. Austin, Texas: The New Media Consortium, 2012.

JOHNSON, L. et al. Technology Outlook for Brazilian Primary and Secondary Education 2012 2017: an NMC Horizon Project Sector Analysis. Austin, Texas: The New Media Consortium, 2012.

LEMOS, A. Cibercultura e mobilidade: a era da conexão. In: LEÃO, L. Derivas: cartografia do ciberespaço. São Paulo: Annablume, 2004. p. 17-44.

Cibercultura. Porto Alegre: Sulina, 2007. 
LEMOS, A.; LÉVY, P. O futuro da internet. São Paulo: Paulus, 2010.

LÉVY, P. A conexão planetária. São Paulo: Editora 34, 2001.

MARTINDALE, T.; DOWDY, M. Personal learning environments. In: VELETSIANOS, G. (Org.). Emerging technologies in distance education. Canada: Athabasca University, 2010. p. 177-193.

McLOUGHLIN, C.; LEE, M. Pedagogy 2.0: critical challenges and responses to web 2.0 and social software in tertiary teaching. In: LEE, M.; MCLOUGHLIN, C. (Eds.). Web 2.0-based elearning: applying social informatics for tertiary teaching. Hershey, PA: Information Science Reference, 2011. p. 43-69.

MOTA, J. Personal learning environments: contributos para uma discussão do conceito. Educação, Formação \& Tecnologias, v. 2, n. 2, p. 5-21, 2009.

O'REILLY, T. What is web 2.0: design patterns and business models for the next generation of software. Communications \& Strategies, v. 65, n. 1, p. 17-37, 2007.

PISANI, F.; PIOTET, D. Como a web transforma o mundo. São Paulo: Senac, 2010.

PIAGET, Jean. Estudos sociológicos. Rio de Janeiro: Forense, 1973.

ROSCHELLE, J.; PEA, R. A walk on the wild side: how wireless handhelds may change computer-supported collaborative learnin. International Conference on Computer-Supported Collaborative Learning, Colorado, p. 7-11, jan. 2002.

SACCOL, A. I. C. Z.; SCHLEMMER, E.; BARBOSA, J. L. V. M-learning e u-learning: novas perspectivas da aprendizagem móvel e ubíqua. São Paulo: Pearson Prentice Hall, 2010. v. 1.

SCLATER, N. Web 2.0, personal learning environments and the future of learning management systems. Boulder, Colorado: Educause, 2008.

SILVA, M. G. M.; CONSOLO, A. T. Mobile learning - uso de dispositivos móveis como auxiliar na mediação pedagógica de cursos a distância. In: REUNIÃO ANUAL DA SBPC, 60, 2008, Campinas. Anais eletrônicos. São Paulo: SBPC/Unicamp, 2008. p. 1-10. Disponível em: <http://www. sbpcnet.org.br/livro/60ra/resumos/resumos /R4675-1.html>. Acesso em: 25 jan. 2011.

SPYER, Juliano. Conectado. Rio de Janeiro: Jorge Zahar, 2007.

TIC EDUCAÇÃO 2010. Pesquisa sobre o uso das tecnologias de informação e comunicação no Brasil. São Paulo: Comitê Gestor da Internet no Brasil, 2011.

TIC EDUCAÇÃO 2011. ___ São Paulo: Comitê Gestor da Internet no Brasil, 2012.

UNESCO. Padrões de competência em TIC para professores. 2009. 